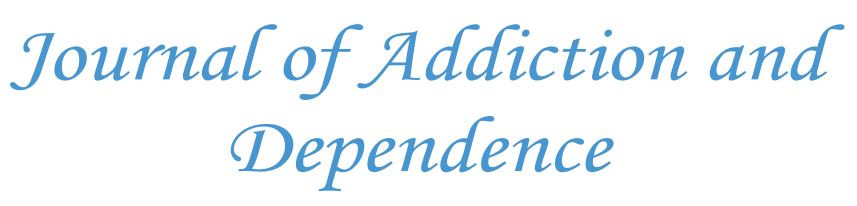

\title{
Development of Tolerance to Effects of Ethanol Depends on its Concentration in the Stomach
}

\author{
Sergey Sudakov*, Valentina Bashkatova, Elena Alexeeva, Natalia Bogdanova, Galina Nazarova
}

P. K. Anokhin Research Institute of Normal Physiology, Baltiyskaya ul. 8, Moscow, Russia

*Corresponding author: Sergey Sudakov, Ph.D., MD, P.K. Anokhin Research Institute of Normal Physiology, Baltiyskaya ul. 8, Moscow, 125315, Russia; Tel: +7(495) 601-00-45; Fax: +7(499) 231-00-45, E-mail: s-sudakov@nphys.ru

\begin{abstract}
Background: The problem of alcohol dependence, as well as the repercussion of alcohol consumption is one of the most dramatic and socially relevant problems for modern society.

Aims: Studying the development of tolerance to anxiolytic, psycho stimulant and analgesic effects of ethanol upon repeated intragastric administration of ethanol in the same dose, but in various volumes.

Methods: Male Wistar rats were treated with ethanol at the same dose $(2 \mathrm{~g} / \mathrm{kg})$, but

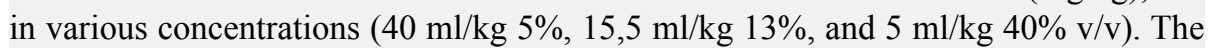
level of anxiety and locomotor activity of animals were evaluated in the elevated plus maze. The analgesic effect of ethanol was studied in the hot plate test.

Results: Intragastric administration of ethanol in a dose of $2 \mathrm{~g} / \mathrm{kg}$ had the anxiolytic, psychostimulant, and analgesic effects. Tolerance to the psychostimulant and analgesic effects develops most rapidly after treatment with small amounts of high-concentration ethanol. By contrast, tolerance to an anxiolytic action was formed rapidly after administration of large amounts of low-concentration ethanol.

Conclusions: 1 . The development of tolerance to various effects of ethanol depends on its concentration and gastric distention with the administered volume. 2 . The development of tolerance to various effects of ethanol depends differently on the volume and concentration. 3. These results support our hypothesis that tolerance to the effect of ethanol is mainly related to its influence on the activity of gastric receptors, which mediates a variety of changes in the central nervous mechanisms.
\end{abstract}

Received Date: October 04, 2016

Accepted Date: November 04, 2016

Published Date: November 08, 2016

Citation: Sudakov, S.K., et al. Development of Tolerance to Effects of Ethanol Depends on its Concentration in the Stomach. (2016) J Addict Depend 2(2): 121- 125.

\section{DOI: $10.15436 / 2471-061 X-16-032$}

Keywords: Ethanol; Tolerance; Analgesic effect; Anxiety; Locomotor activity

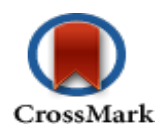

\section{Introduction}

The problem of alcohol dependence, as well as the repercussion of alcohol consumption is one of the most dramatic and socially relevant problems for modern society ${ }^{[1]}$. Despite of the large number of studies devoted to this problem, some aspects of the physiological and neurochemical effects of ethanol are still poorly understood. One of these problems is the problem of tolerance to different effects of ethanol. Tolerance is usually considered as a reduced reaction to repeated administration of different psychoactive substances, including ethanol. Thus, there is the adaptation to exogenous psychoactive substance. To achieve a certain effect of the substance, it is necessary to increase its dose. Published data show that the development of tolerance to ethanol may be due to the mechanisms of receptor interaction ${ }^{[2,3]}$. It is supposed that its effects may be mediated by the systems of gamma-Aminobutyric acid or N-methyl-D-aspartate receptors ${ }^{[4,5]}$.

Due to the fact that specific receptors for ethanol in Central Nervous System (CNS) have not yet been found, we assumed that the development of tolerance to its effects may be partially related to a direct action of ethanol on the gastric mucosa and intragastric receptors. Our previous experiments revealed that variations in the activity of intragastric receptors indirectly lead to changes in the activity of similar receptors in the CNS. It 
should be emphasized that the influence on opioid receptors in the stomach leads to a change in the activity of the brain opioid system $^{[6,7]}$.

This work was designed to study the development of tolerance upon repeated intragastric administration of ethanol in the same dose, but in various volumes. We hypothesized that different amounts and concentrations of ethanol will affect chemoreceptors and mechanoreceptors in the wall of the stomach.

\section{Materials and methods}

\section{Animal preparations}

Experiments were performed on 48 male Wistar rats weighing $180-210 \mathrm{~g}$. The animals were housed in ventilated cages (Techniplast, Italy) with a free access to water and standard food. The artificial light regimen was from 23:00 to 11:00. The experiment was conducted in accordance with the Order № 267 of the Russian Ministry of Health (19.06.2003), "Rules of Studies on Experimental Animals" (approved by the Ethics Committee of the P. K. Anokhin Institute of Normal Physiology; protocol No. 1, 3.09.2005), and requirements of the World Society for the Protection of Animals (WSPA) and European Convention for the Protection of Experimental Animals.

\section{Experimental procedure}

The anxiolytic, psychostimulant, and analgesic effects of ethanol were studied for 7 days. Ethanol or water was administered once a day directly into the stomach using a special metal catheter. Two hours before treatment, the rats were deprived of food and water. The animals were divided into 6 groups of 8 animals each. The rats of three experimental groups received ethanol solutions at a dose of $2 \mathrm{~g} / \mathrm{kg}$ in various concentrations and different volumes. Group 1 animals received ethanol in a volume of $5 \mathrm{ml} / \mathrm{kg}$, which corresponds to a concentration of $40 \%(\mathrm{v} / \mathrm{v})$; group 2 animals received ethanol in a volume of 15.5 $\mathrm{ml} / \mathrm{kg}$, which corresponds to a concentration of $13 \%(\mathrm{v} / \mathrm{v})$; and group 3 animals received ethanol in a volume of $40 \mathrm{ml} / \mathrm{kg}$, which corresponds to a concentration of $5 \%(\mathrm{v} / \mathrm{v})$. The rats of control groups 1,2 , and 3 received standard bottled water $(5,15.5$, and $40 \mathrm{ml} / \mathrm{kg}$, respectively).

\section{Elevated plus maze test}

Twenty minutes after administration of study solutions, rats were placed in the Elevated Plus Maze (EPM) for 5 minutes to evaluate the level of anxiety-related behaviors (estimated as the time spent in the open arms of $\mathrm{EPM}^{[8]}$ ). Locomotor activity was determined by the total number of crossings episodes from one arm of EPM to another. An EPM device was of the basic modification (Columbus Instruments, USA) and had the following characteristics: length of each of the four arms of the maze, $50 \mathrm{~cm}$; width, $15 \mathrm{~cm}$; height of opaque walls in the two opposite closed arms of the maze, $15 \mathrm{~cm}$; and central area, $15 \times 15 \mathrm{~cm}$. EPM was elevated above the floor at a height of $75 \mathrm{~cm}$. At the beginning of the experiment, rats were placed in the center of the device. These procedures were repeated daily for 7 days.

\section{Hot plate test}

Five minutes after the end of each session in EPM, the animals were placed in a hot plate device. The metal surface had a temperature of $56^{\circ} \mathrm{C}$ degrees (TSE, Germany). The latency of hind limb licking was evaluated. When the licking episode did not occur within 60 seconds, the rats were removed from the device $^{[9]}$. These procedures were repeated daily for 7 days.

\section{Statistics}

The data are expressed as the means and Standard Error of the Means (SEM). The results were analyzed by nonparametric Mann - Whitney U test.

\section{Results}

Development of tolerance to the anxiolytic effect of treatment with ethanol at the same dose, but in various volumes Administration of ethanol solutions at a dose of $2 \mathrm{~g} /$ $\mathrm{kg}$ in all volumes $(5,15.5$, and $40 \mathrm{ml} / \mathrm{kg})$ produced a strong anxiolytic effect on day 1 of the experiment (Figure 1). Treatment with ethanol solution in a volume of $5 \mathrm{ml} / \mathrm{kg}$ was followed by the disappearance of an anxiolytic effect on day 5 of the experiment (Figure 1a). The anxiolytic effect was unstable after administration of ethanol solution in a volume of $15.5 \mathrm{ml} / \mathrm{kg}$ (Figure 1b). The increased time spent in the open arms of EPM after treatment with $40 \mathrm{ml} / \mathrm{kg}$ ethanol was not observed on day 3 of the experiment (Figure 1c). Thus, our results show that the development of tolerance to an anxiolytic effect of ethanol depends on the concentration and volume of ethanol solutions.
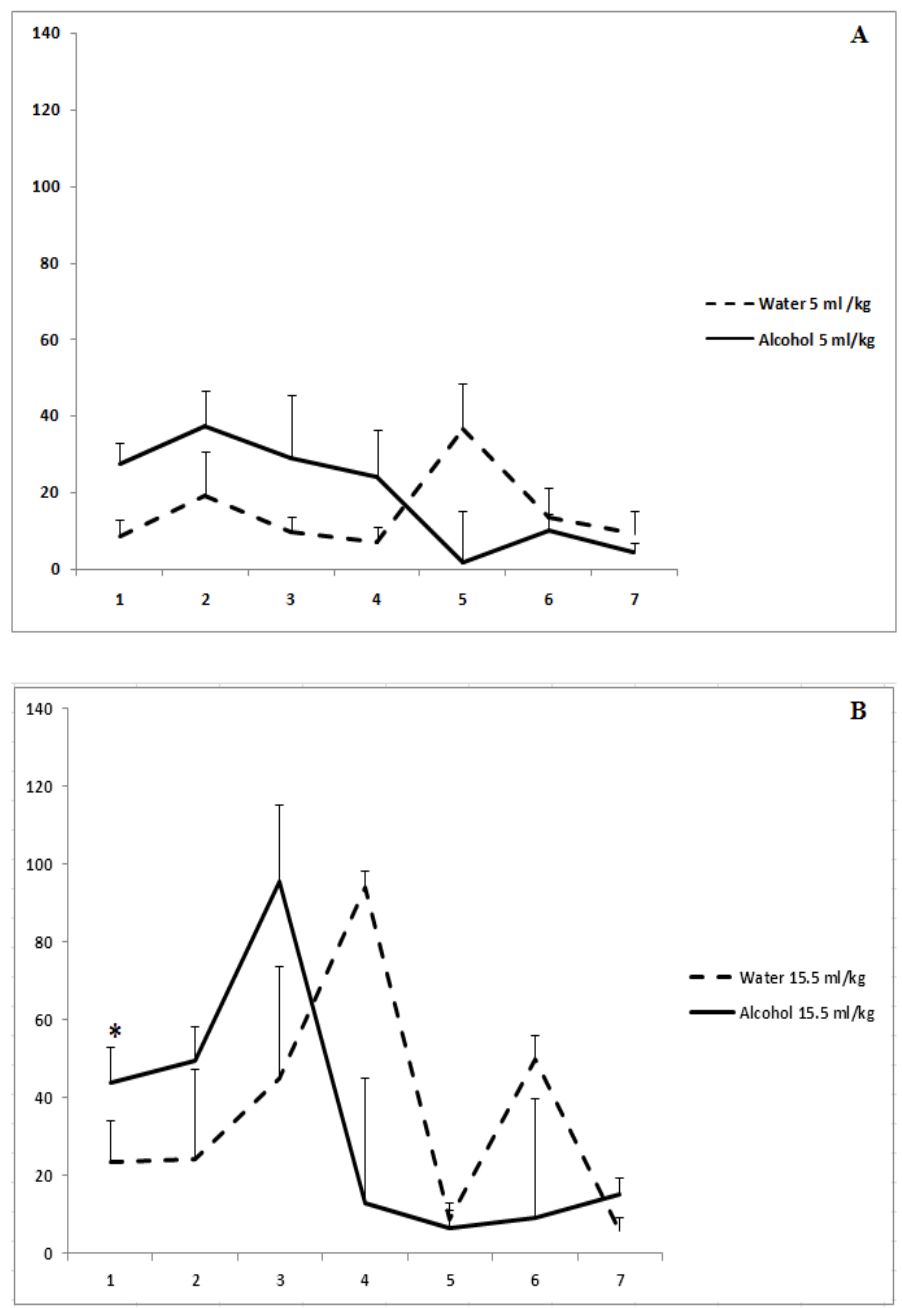


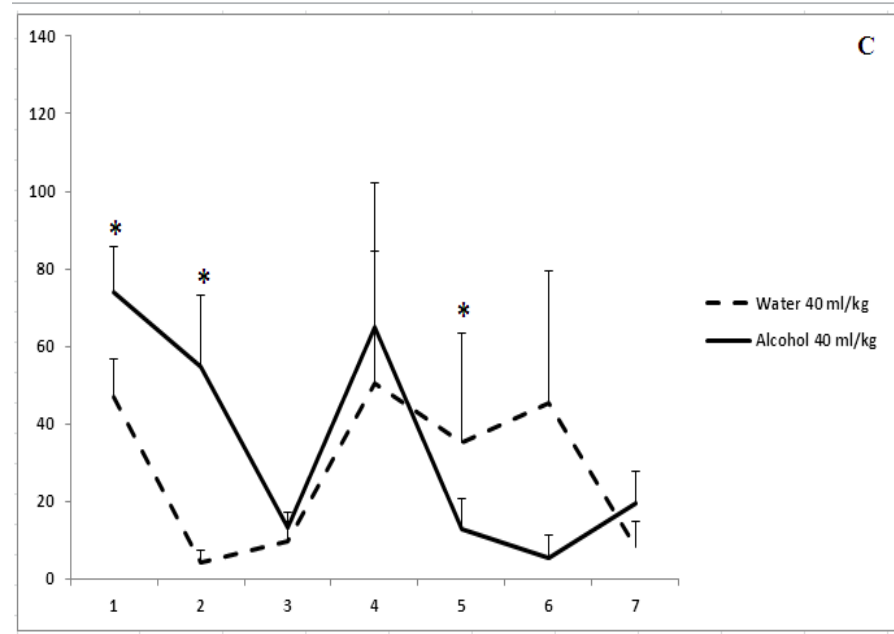

Figure 1: The effect of the administration of different volumes of ethanol at dose of $2 \mathrm{~g} / \mathrm{kg}$ on level of anxiety in rats.

On the ordinate axis - the time spent on the open arms of the elevated plus maze(s). On the horizontal axis - time of the experiment (days). . $* \mathrm{P}<0.05$ vs. controls. Values are mean \pm s.e.m.,

Development of tolerance to the psychostimulant effect of treatment with ethanol at the same dose, but in various volumes

Administration of ethanol in study volumes produced a significant increase in locomotor activity of rats on day 1 of the experiment (Figure $2 \mathrm{~b}, \mathrm{c}$ ). The psychostimulant effect of ethanol solution in a volume of $5 \mathrm{ml} / \mathrm{kg}$ was revealed on day 6 of the experiment (Figure $2 \mathrm{a}$ ). The rats treated with ethanol solution in a volume of $15.5 \mathrm{ml} / \mathrm{kg}$ demonstrated a varying stimulatory response. However, the effect of ethanol remained to be significant on day 7 (Figure 2b). Administration of ethanol solution in a volume of $40 \mathrm{ml} / \mathrm{kg}$ induced a pronounced increase in locomotor activity as compared to control animals (over 7 days of the experiment; Figure 2c). Thus, the development of tolerance to a psychostimulant effect of ethanol was observed after administration of ethanol solution only in a volume of $5 \mathrm{ml} / \mathrm{kg}$.

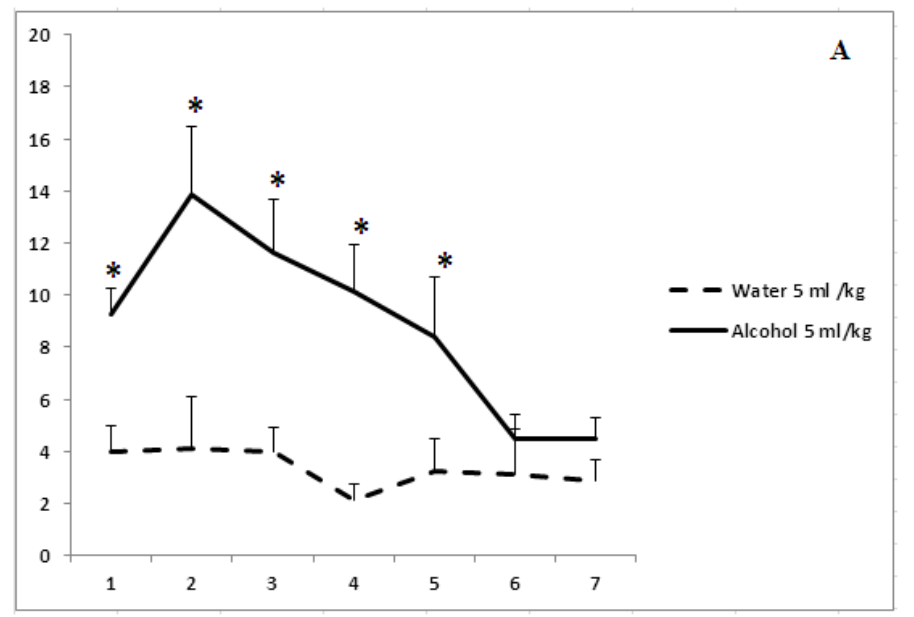

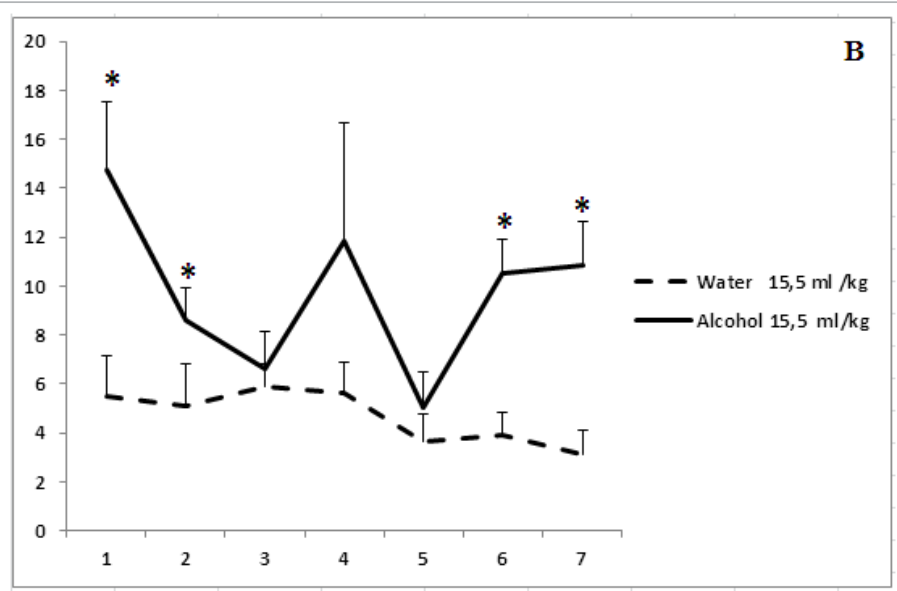

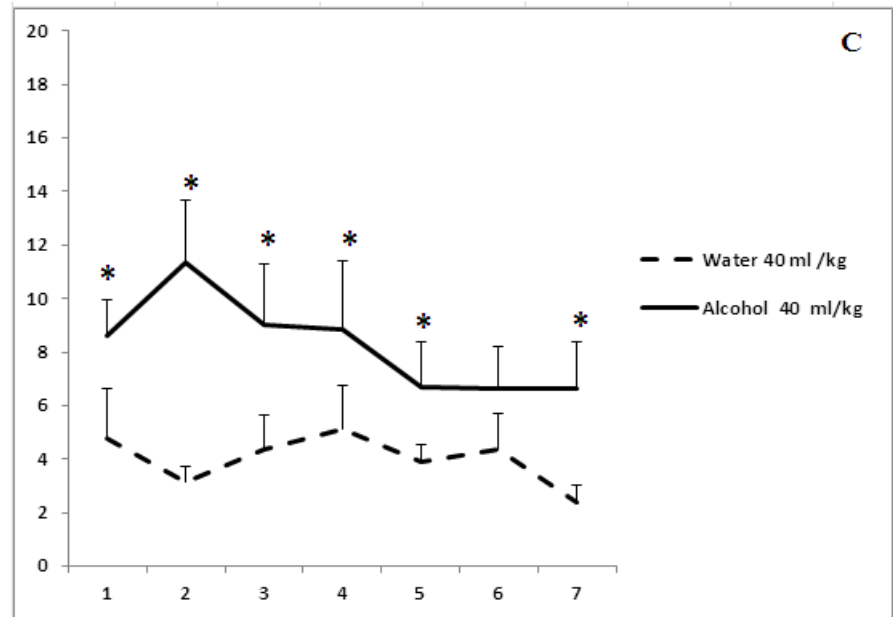

Figure 2; The effect of the administration of different volumes of ethanol at dose of $2 \mathrm{~g} / \mathrm{kg}$ on locomotor activity in rats.

On the ordinate axis - the total number of crossings of border's rays in elevated plus maze. On the horizontal axis - time of the experiment (days). . $* \mathrm{P}<0.05$ vs. controls. Values are mean \pm s.e.m.,

\section{Development of tolerance to the analgesic effect of treatment with ethanol at the same dose, but in various volumes}

Administration of ethanol in study volumes was followed by significantly delay of paws-licking episodes beginning from the first days of observations (Figure 3 ). The analgesic effect disappeared on day 3 of the experiment after treatment with ethanol in a volume of $5 \mathrm{ml} / \mathrm{kg}$. The analgesic effect of $15.5 \mathrm{ml} /$ $\mathrm{kg}$ ethanol disappeared on day 5 of the experiment (Figure $3 \mathrm{~b}$ ). The rats treated with the highest volume of ethanol $(40 \mathrm{ml} / \mathrm{kg})$ exhibited a lack of tolerance to the analgesic effects of ethanol over 7 days of the experiment (Figure 3c). Thus, the development of tolerance to an analgesic effect of ethanol depends on the concentration and volume of ethanol solutions. 

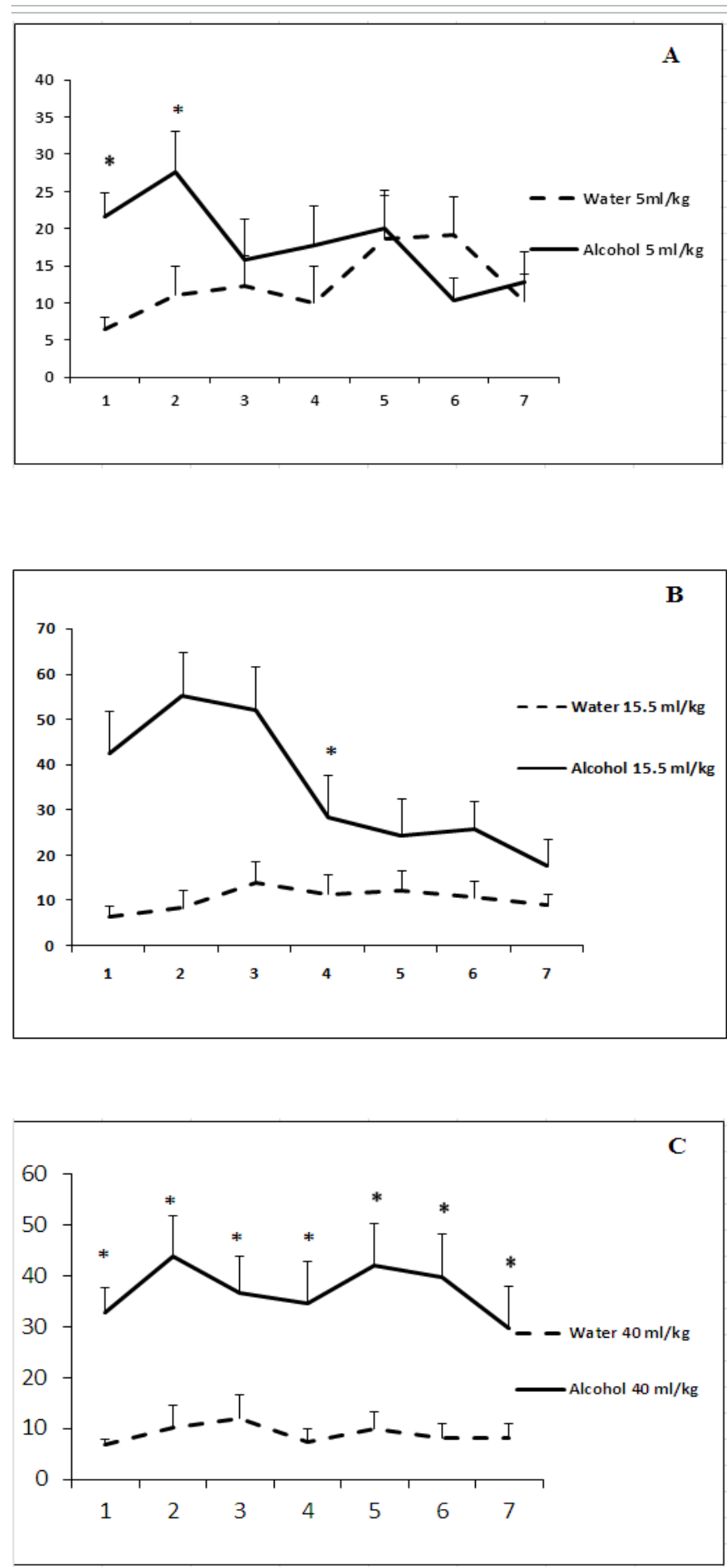

Figure 3: The effect of the administration of different volumes of ethanol at a dose of $2 \mathrm{~g} / \mathrm{kg}$ on pain sensitivity.

On the ordinate axis - the start time of licking of paws in the test "hot plate" (s). On the horizontal axis - time of the experiment (days). . $* \mathrm{P}<$ 0.05 vs. controls. Values are mean \pm s.e.m.,

\section{Discussion}

Our results show that the development of tolerance to various effects of ethanol depends on gastric distention by the administered volume and ethanol concentration. Tolerance to the psychostimulant and analgesic effects develops most rapidly after treatment with small amounts of high-concentration ethanol.
By contrast, tolerance to an anxiolytic action was formed rapidly after administration of large amounts of low-concentration ethanol. We conclude that the concentration and volume of an ethanol-containing liquid are very important for the development of tolerance to different effects of ethanol at the same dose.

One of the major limitations of used method is that all rats (as control as experimental) in our work were re-exposed to the EPM and hot plate for 7 times. This procedure is quite uncommon, as it has been repeatedly reported that rat performance at these tests is remarkably influenced by previous exposures. However, we evaluate the formation of tolerance in comparison with control groups, which also may show changes caused by the repeated tests.

It should be noted that despite high importance of studying the effects of alcohol, only small number of experimental researches were devoted to the evaluation of tolerance mechanisms. Most of them are focused on the influence of ethanol on the activity of certain receptors in the $\mathrm{CNS}^{[10,11]}$. Thus, it was shown that different subtypes of opioid receptors are involved in the formation of tolerance to various effects of ethanol ${ }^{[12,13,14]}$. It was demonstrated that chronic ethanol drinking alters the ability of $\mu$-opioid receptor to endocytose opioid peptides, and consequently, promotes tolerance to the effects of opioids ${ }^{[15]}$. It can be assumed that a change in the binding characteristics of opioid receptors and neuropeptides in brain structures under repeated administrations of ethanol can determine the development of tolerance to different effects of ethanol, including the anxiolytic, sedative, and other effects.

Our previous experiments showed that the level of anxiety (i.e., behavior ${ }^{[16]}$, locomotor activity ${ }^{[17]}$, and pain sensitivity $^{[18]}$ ) in rats is modified by a change in the activity of gastric receptors and, particularly, of opioid receptors. Published data indicate that a change in the activity of gastric receptors mediates variations in the activity of similar receptors in the CNS and, partially, modifies different effects of ethanol ${ }^{[6]}$.

Previous studies revealed that the lowest concentration of ethanol in the blood is observed after consumption of large volumes of beer (as compared to the effect of smaller volumes of strong alcohol $)^{[19]}$. It can be suggested that a correlation exists between the development of tolerance to stimulating and analgesic effects of ethanol and its concentration in the blood.

\section{Conclusions}

1. The development of tolerance to various effects of ethanol depends on its concentration and gastric distention by the administered volume.

2. The development of tolerance to various effects of ethanol depends differently on the volume and concentration.

3 . These results support our hypothesis that tolerance to the effect of ethanol is mainly related to its influence on the activity of gastric receptors, which mediates a variety of changes in the central nervous mechanisms.

\section{Acknowledgments}

This work was supported by the Russian Foundation for Basic Research (grant № 15-04-01690).

\section{Conflict of Interest: None}




\section{References}

1. Heinz, A.J., Beck. A., Meyer-Lindenberg. A., et al. Cognitive and neurobiological mechanisms of alcohol-related aggression. (2011) Nat Rev Neurosci 12(7): 400-413.

2. Faingold, C.L., N'Gouemo P., Riaz A. Ethanol and neurotransmitter interactions-from molecular to integrative effects. (1998) Prog Neurobiol 55(5): 509-535.

3. Dar, M.S. Functional interaction and cross-tolerance between ethanol and $\triangle 9$-THC: possible modulation by mouse cerebellar adenosinergic A1/GABAergic-A receptors. (2014) Behav Brain Res 270: 287-294.

4. Enoch, M.A. The role of GABA(A) receptors in the development of alcoholism. (2008) Pharmacol Biochem Behav 90(1): 95-104.

5. Nagy, J. Alcohol related changes in regulation of NMDA receptor functions. (2008) Curr Neuropharmacol 6(1): 39-54.

6. Proskuryakova, T.V., Shokhonova, V.A., Chumakova, Y.A., et al. Modulation of peripheral opioid receptors affects the concentration of mu-opioid receptors in rat brain. (2009) Bull Exp Biol Med 148(3): 357-359.

7. Sudakov, S.K., Bashkatova, V.G., Kolpakov, A.A., et al. Loperamide effects on anxiety level and feeding behavior in rats. Role of vagal afferentation. (2012) Bull Exp Biol Med 153(5): 717-719.

8. Pellow, S., Chopin, P., File, E., et al. Validation of open:closed arm entries in an elevated plus-maze as a measure of anxiety in the rat. (1985) J Neurosci Methods 14(3): 149-167.

9. Carter, R.B. Differentiating analgesic and non-analgesic drug activities on rat hot plate: effect of behavioral endpoint. (1991) Pain 47(2): 211-220

10. Follesa, P., Biggio, F., Talani, G., et al. Neurosteroids, GABA-A receptors, and ethanol dependence. (2006) Psychopharmacology (Berl) 186(3): 267-280.
11. Wu, P.H., Coultrap, S., Browning, M.D., et al. Correlated changes in NMDA receptor phosphorylation, functional activity, and sedation by chronic ethanol consumption. (2010) J Neurochem 115(5): 1112-1122. 12. Lindholm, S., Rosin, A., Dahlin, I., et al. Ethanol alters the effect of kappa receptor ligands on dopamine release in the nucleus accumbens. (2007) Physiol Behav 92(1-2): 167-171.

13. Llorente, J., Withey S., Rivero G., et al. Ethanol reversal of cellular tolerance to morphine in rat locus coeruleus neurons. (2013) Mol Pharmacol 84(2): 252-260.

14. Hull, L.C., Gabra, B.H., Bailey, C.P., et al. Reversal of morphine analgesic tolerance by ethanol in the mouse. (2013) J Pharmacol Exp Ther 345(3): 512-519.

15. He, L., Whistler, J.L. Chronic ethanol consumption in rats produces opioid antinociceptive tolerance through inhibition of mu opioid receptor endocytosis. (2011) PLOS One 6(5): e19372.

16. Sudakov, S.K., Bashkatova, V.G., Kolpakov, A.A., et al. Peripheral administration of loperamide and methylnaloxone decreases the degree of anxiety in rats. (2010) Bull Exp Biol Med 149(3): 273-275.

17. Sudakov, S.K., Nazarova, G.A., Kolyasnikova, K.N., et al. Effect of peripheral administration of peptide ligands of $\delta$-opioid receptors on anxiety level and locomotor activity of rats. (2011) Bull Exp Biol Med 151(6): 661-663.

18. Sudakov, S.K., Trigub, M.M. Hypothesis on reciprocal interactions between the central and peripheral components of the endogenous opioid system. (2008) Bull Exp Biol Med 146(6): 663-666.

19. Mitchell, M.C., Teigen, E.L., Ramchandani, V.A. Absorption and peak blood alcohol concentration after drinking beer, wine, or spirits. (2014) Alcohol Clin Exp Res 38(5): 1200-1204.
Ommega Online Publishers

Journal Title: Journal of Addiction and Dependence(JAD)

Journal Short Name: J Addict Depend
ISSN no: 2471-061X

E-mail: addiction.depend@ommegaonline.org

Website: www.ommegaonline.org 